\title{
PENGARUH PANJANG SERAT TERHADAP SIFAT BENDING KOMPOSIT POLIESTER BERPENGUAT SERAT AGAVE CANTULA
}

\author{
Kristomus Boimau'), Jahirwan UT Jasron ${ }^{2)}$, Rima N. Selan ${ }^{3)}$, Dona Fiah ${ }^{4)}$ \\ ${ }^{1,2,3,4)}$ Teknik Mesin, Fakultas Sains dan Teknik, Universitas Nusa Cendana \\ E-mail: ${ }^{1}$ kristomus.boimau@staf.undana.ac.id
}

\begin{abstract}
Abstrak
Penggunaan serat alam sebagai bahan penguat dalam bidang rekayasa material komposit polimer semakin diminati oleh peneliti dan juga oleh praktisi dunia industri. Hal ini disebakan karena serat alam tidak mencemari lingkungan dan mudah didaur ulang, sedangkan limbah serat sintesis sebaliknya mencemari lingkungan. Penelitian ini bertuuan untuk mengetahui pengaruh panjang serat agave cantula terhadap sifat bending komposite polyester. Bahan yang digunakan dalam penelitian ini adalah serat agave cantula, matrik poliester dan $\mathrm{NaOH}$. Serat diperoleh dari batang daun agave cantula yang diserut menggunakan pisau. Sebelum serat digunakan sebagai penguat pada penelitian ini, terlebih dahulu serat diberi perlakuan perendaman dalam larutan alkali dengan konsentrasi larutan sebesar $2 \%$ selama 4 jam. Setelah perendaman, serat dicuci dengan air bersih untuk menghilangkan $\mathrm{NaOH}$ dari serat. Panjang serat yang digunakan adalah $2 \mathrm{~cm}, 4 \mathrm{~cm}$ dan $6 \mathrm{~cm}$. Komposisi campuran serat dan matrik didasarkan pada aturan Rule of Mixture (RoM), dengan fraksi volume serat sebesar 30\%. Komposit dicetak dengan metode hand ly up diikuti penekanan selama 24 jam, sedangkan specimen uji bending dibuat sesuai standar ASTM D790 dan diuji dengan alat uji UTM. Hasil pengujian bending menunjukan bahwa komposit yang diperkuat oleh serat yang diberi perlakuan alkali memiliki kekuatan bending yang lebih tinggi dibandingkan dengan komposit berpenguat serat tanpa perlakuan alkali. Komposit dengan panjang $6 \mathrm{~cm}$ memiliki nilai tegangan bending yang lebih tinggi dibandingkan dengan pajang $2 \mathrm{~cm}$ dan $4 \mathrm{~cm}$.
\end{abstract}

Kata Kunci: Alkali, Agave Cantula, Bending, Komposit Poliester, Panjang Serat

\section{Abstract}

The use of natural fibers as a reinforcing material in the field of polymer composite materials engineering is increasingly in demand by researchers as well as by practitioners of the industrial world. This is because natural fibers do not pollute the environment and are easily recycled, while synthetic fiber waste otherwise pollutes the environment. This study aims to determine the effect of the agave cantula fiber length on the bending properties of polyester composites. The materials used in this study were agave cantula fiber, polyester matrix, and $\mathrm{NaOH}$. The fiber is obtained from the stems of the agave cantula which are shaved with a knife. Before the fiber was used as reinforcement in this study, the fiber was first treated with immersion in an alkaline solution with a solution concentration of $2 \%$ for 4 hours. After soaking, the fibers are washed with clean water to remove $\mathrm{NaOH}$ from the fibers. The fiber length used is $2 \mathrm{~cm}, 4 \mathrm{~cm}$, and $6 \mathrm{~cm}$. The composition of the fiber mixture and matrix is based on the Rule of Mixture (RoM), with a fiber volume fraction of 30\%. Furthermore, the composite was printed using the handly up method followed by pressing for 24 hours, 
while the bending test specimen was made according to the ASTM D790 standard and tested with the UTM test equipment. The results of the bending test show that the composite reinforced by the fiber treated with alkali has a higher bending strength than the fiber-reinforced composite without the alkali treatment. Composites with a length of $6 \mathrm{~cm}$ have a higher bending stress value compared to $2 \mathrm{~cm}$ and $4 \mathrm{~cm}$ lengths.

Keywords: Alkali, Agave Cantula, Bending, Polyester Composite, Fiber Length 


\section{PENDAHULUAN}

Ilmu material berkembang sangat pesat dalam satu dekade terakhir ini, khususnya material komposit polimer berpenguat serat alam. Penggunaan serat alam yang semakin meningkat sebagai media penguat material komposit polimer dipengaruhi oleh beberapa faktor yang dominan, antara lain karena sangat ekonomis (biaya produksi murah), ramah lingkungan, dapat terurai secara alami, ringan, tidak beracun, sifat spesifik tinggi, dapat diperbaharui, ekspansi termal rendah, tahan terhadap korosi, ramah lingkungan dan dapat terurai secara hayati [1].

Penggunaan serat alam juga merupakan langkah kongkrit menjaga kelestarian lingkungan dari ancaman efek rumah kaca karena zat karbon yang dihasilkan sangat rendah jika dibandingkan dengan penggunaan serat sintesis seperti serat glass [2]

Namun di sisi lain, serat alam memiliki kelemahan yaitu tidak cocok jika digabungkan dengan polimer. Ketidakcocokan ini disebabkan oleh sifat serat alam yang mudah sekali menyerap air (hidrophilic) sedangkan sebaliknya polimer bersifat tidak menyerap air (hydrophobic). Dampak negatif dari ketidakcocokan ini mengakibatkan lemahnya ikatan interfacial antara serat alam dan matrik yang otomatis akan mempengaruhi sifat mekanik dari komposit polimer berpenguat serat alam. Sifat ini dapat diminimalisir dengan melakukan perlakuan kimia terhadap serat alam dengan menggunakan $\mathrm{NaOH}$, silane, Chromium sulfate $\left(\mathrm{Cr}_{2}\left(\mathrm{SO}_{4}\right)_{3}\right.$. Beberapa peneliti menyatakan bahwa perlakuan kimia pada serat alam dapat membersihkan serat dari kotoran dan lignin yang menempel, permukaan serat menjadi kasar sehingga mampu meningkatkan kemampuan daya ikat antar muka serat dan matrik [3-4]

Beberapa contoh serat alam yang telah digunakan oleh para peneliti sebagai penguat material komposit polimer, antara lain rami, kenaf, salak, bambu, pisang, abaca [4-5]. Selain serat alam yang telah disebutkan di atas, ada juga potensi local di wilayah pulau Timor, Nusa Tenggara Timut yaitu serat buah lontar, agave cantula, gewang dan widuri yang telah diteliti penggunaannya sebagai penguat material komposit polyester [6-8]. Kajian sifat mekanik komposit yang diperkuat oleh serat alam telah diteliti dan dilaporkan oleh beberapa peneliti. Beberapa diantaranya melaporkan bahwa ukuran panjang serat memberikan pengaruh yang 
signifikan terhadap sifat tarik, bending dan juga impak. Semakin panjang serat, kekuatan mekanik komposit semakin meningkat [9]. Penggunaan serat salak sebagai penguat komposit HDPE dengan variasi panjang serat (1, 3, 5, 7, $9 \mathrm{~mm})$ menunjukkan bahwa kekuatan impak komposit cenderung meningkat seiring dengan bertambahnya panjang serat [10]. Pada penelitian yang lain, panjang serat daun gewang juga memberikan dampak terhadap kekuatan bending komposit polyester. Pengaruh Panjang Serat Terhadap Sifat Bending Komposit Poliester Berpenguat Serat Daun Gewang. [6]

Hasil tersebut sejalan juga dengan komposit epoxy berpenguat serat pisang, yang mana semakin panjang serat yang digunakan menunjukkan bahwa kekuatan impak juga cenderung naik [11].

Peneliti lain juga melaporkan bahwa serat carbon dengan panjang $80 \mu \mathrm{m}$ memiliki kekuatan tarik yang lebih tinggi dibandingkan dengan panjang serat $30 \mu \mathrm{m}$ dan 50 $\mu \mathrm{m}$. Namun pada penggunaan serat carbon dengan panjang $110 \mu \mathrm{m}$ dan $140 \mu \mathrm{m}$, terlihat bahwa kekuatan tarik mengalami penurunan [12]

\section{METODE PENELITIAN}

Material yang digunakan dalam penelitian ini adalah serat agave cantula, resin polyester dan $\mathrm{NaOH}$. Serat agave cantula diperoleh dari batang daun agave cantula melalui proses menyerut. Sebelum serat digunakan sebagai penguat pada penelitian ini, terlebih dahulu serat diberi perlakuan perendaman dalam larutan alkali dengan konsentrasi larutan sebesar 2\% selama 4 jam. Setelah diberi perlakuan alkali, serat dicuci dengan air bersih untuk menghilangkan $\mathrm{NaOH}$ yang masih ada pada serat. Selanjutnya serat dikeringkan dengan cara dijemur. Serat yang telah kering, dipotong dengan ukuran panjang $2 \mathrm{~cm}$, $4 \mathrm{~cm}$ dan $6 \mathrm{~cm}$. Komposit dibuat dengan metode hand ly up diikuti penekanan selama 24 jam. Perbandingan komposisi campuran resin polyester dan serat dihitung sesuai aturan rule of mixture (RoM), dengan fraksi volume serat sebesar 30\%. Perhitungan fraksi volume serat $\left(\mathrm{V}_{\mathrm{f}}\right)$ menggunakan persamaan berikut:

$$
\mathrm{V}_{\mathrm{f}}=\frac{V f}{V c},
$$

$\begin{array}{lll}\text { dimana: } & \mathrm{V}_{\mathrm{f}} & =\text { Fraksi Volume serat }(\%) \\ & \mathrm{v}_{\mathrm{f}} & =\text { volume serat }\left(\mathrm{cm}^{3}\right)\end{array}$ 


$$
\mathrm{v}_{\mathrm{c}} \quad=\text { Volume composit }\left(\mathrm{cm}^{3}\right)
$$

Komposit hasil cetakan dibentuk menjadi specimen uji menurut standard ASTM D790 dengan cara dipotong menggunakan gerinda. Pengukuran ketebalan dan lebar specimen menggunakan alat ukur digital kaliper merk krisbow. Tahapan penelitian secara umum dapat dilihat pada gambar di bawah ini.

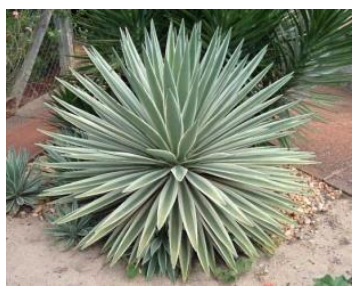

a

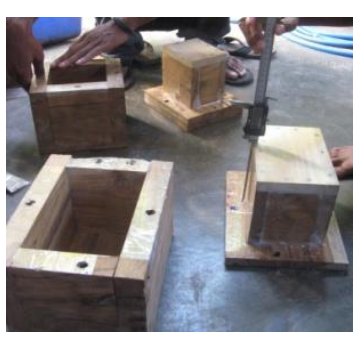

f 7

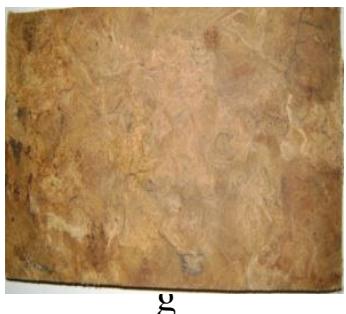

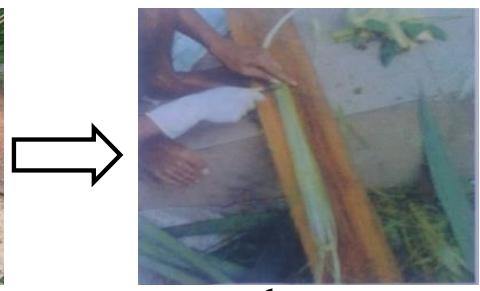

b

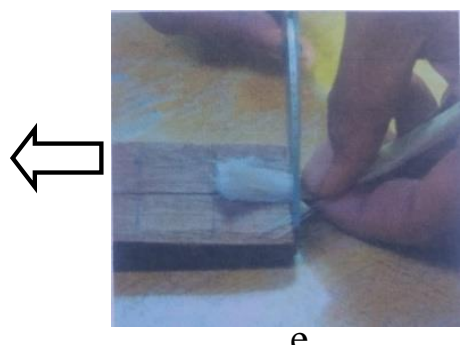

e

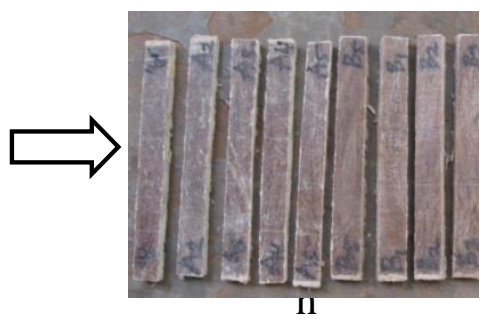

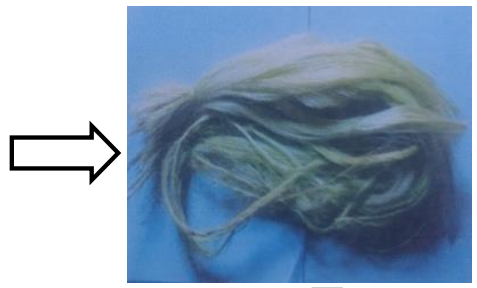
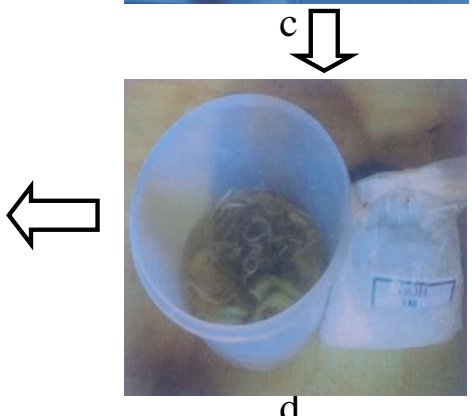

d

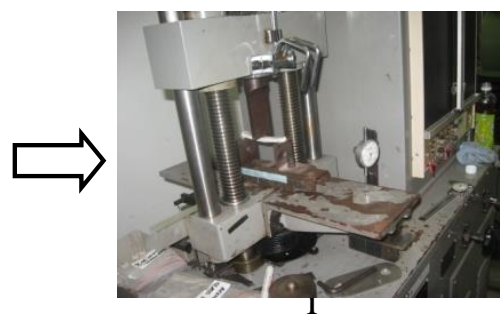

Gambar 1. a). Tanaman Agave Cantula, b). Proses Menyerut, c). Hasil serutan berupa serat, d). Perlakuan alkali pada serat, e). Pemotongan serat $(2 \mathrm{~cm}, 4 \mathrm{~cm}$, $6 \mathrm{~cm})$, f). Cetakan Komposit, g). Hasil Cetakan, h). Spesimen Uji, i). Pengujian Bending dengan alat UTM.

\section{HASIL DAN PEMBAHASAN}

\section{Hasil Uji Bending}

Pengujian bending yang dilakukan terhadap specimen uji menggunakan alat uji universal testing machine (UTM), diperoleh data-data beban uji (P) dan defleksi $(\delta)$ seperti pada table di bawah ini 
Tabel 1. Data hasil pengujian bending komposit serat tanpa perlakuan $\mathrm{NaOH}$

\begin{tabular}{|c|c|c|c|c|c|c|}
\hline $\begin{array}{c}\text { Panjang } \\
\text { Serat }(\mathrm{cm})\end{array}$ & $\begin{array}{c}\text { Kode } \\
\text { Spesimen }\end{array}$ & $\begin{array}{c}\text { Tebal, d } \\
(\mathrm{mm})\end{array}$ & $\begin{array}{c}\text { Lebar, b } \\
(\mathrm{mm})\end{array}$ & $\begin{array}{c}\text { Panjang } \\
\text { Span (L) }\end{array}$ & $\begin{array}{c}\text { Beban, P } \\
(\mathrm{kg})\end{array}$ & $\begin{array}{c}\text { Defleksi } \\
\text { Maksimum, }\end{array}$ \\
\hline \multirow{6}{*}{2} & $\mathrm{~A} 1$ & 6.8 & 12.85 & 100 & 11.5 & 11 \\
\cline { 2 - 7 } & $\mathrm{A} 2$ & 6.79 & 12.9 & 100 & 9 & 12 \\
\cline { 2 - 7 } & $\mathrm{A} 3$ & 6.98 & 13.2 & 100 & 7.2 & 11 \\
\cline { 2 - 7 } & $\mathrm{A} 4$ & 6.6 & 12.7 & 100 & 8.4 & 10.75 \\
\cline { 2 - 7 } & $\mathrm{A} 5$ & 6.8 & 12.8 & 100 & 8.7 & 11.25 \\
\hline \multirow{4}{*}{4} & $\mathrm{~B} 1$ & 6.18 & 13.8 & 100 & 9 & 12.5 \\
\cline { 2 - 7 } & $\mathrm{B} 2$ & 6.31 & 13.1 & 100 & 9.6 & 12.5 \\
\cline { 2 - 7 } & $\mathrm{B} 3$ & 6.16 & 13.2 & 100 & 12.8 & 10,25 \\
\cline { 2 - 7 } & $\mathrm{B} 4$ & 6.2 & 13.2 & 100 & 10.8 & 11.75 \\
\cline { 2 - 7 } & $\mathrm{B} 5$ & 6.2 & 13.4 & 100 & 12.4 & 12.25 \\
\hline \multirow{4}{*}{6} & $\mathrm{C} 1$ & 6.3 & 13.2 & 100 & 13 & 11 \\
\cline { 2 - 7 } & $\mathrm{C} 2$ & 6.25 & 13.1 & 100 & 13.5 & 13 \\
\cline { 2 - 7 } & $\mathrm{C} 3$ & 6.5 & 13.2 & 100 & 11.7 & 11,5 \\
\cline { 2 - 7 } & $\mathrm{C} 4$ & 6.6 & 13.2 & 100 & 12.6 & 12.25 \\
\cline { 2 - 7 } & $\mathrm{C} 5$ & 6.4 & 13.4 & 100 & 13.8 & 22.75 \\
\hline
\end{tabular}

Tabel 2. Data hasil pengujian bending komposit serat dengan perlakuan $\mathrm{NaOH}$

\begin{tabular}{|c|c|c|c|c|c|c|}
\hline $\begin{array}{c}\text { Panjang } \\
\text { Serat (cm) }\end{array}$ & $\begin{array}{c}\text { Kode } \\
\text { Spesimen }\end{array}$ & $\begin{array}{c}\text { Tebal, d } \\
(\mathrm{mm})\end{array}$ & $\begin{array}{c}\text { Lebar, b } \\
(\mathrm{mm})\end{array}$ & $\begin{array}{c}\text { Panjang } \\
\text { Span (L) }\end{array}$ & $\begin{array}{c}\text { Beban, P } \\
(\mathrm{kg})\end{array}$ & $\begin{array}{c}\text { Defleksi } \\
\text { Maksimum, }\end{array}$ \\
\hline \multirow{4}{*}{2} & D1 & 6.12 & 13.28 & 100 & 9 & 10.5 \\
\cline { 2 - 7 } & D2 & 6.31 & 13.01 & 100 & 10.2 & 10.5 \\
\cline { 2 - 7 } & D3 & 6.16 & 13.2 & 100 & 14.1 & 11 \\
\cline { 2 - 7 } & D4 & 6.21 & 13.3 & 100 & 10.7 & 10.75 \\
\cline { 2 - 7 } & D5 & 6.18 & 13.25 & 100 & 12.5 & 11.25 \\
\hline \multirow{4}{*}{4} & E1 & 6.12 & 13.1 & 100 & 12.2 & 12.2 \\
\cline { 2 - 7 } & E2 & 6.13 & 12.98 & 100 & 15.5 & 15.5 \\
\cline { 2 - 7 } & E3 & 6.1 & 13.1 & 100 & 10.6 & 10.6 \\
\cline { 2 - 7 } & E4 & 6.2 & 13.2 & 100 & 12.7 & 12.7 \\
\cline { 2 - 7 } & E5 & 6.15 & 12.85 & 100 & 13.4 & 13.4 \\
\hline \multirow{4}{*}{6} & F1 & 6.12 & 12.4 & 100 & 14,9 & 8 \\
\cline { 2 - 7 } & F2 & 6.31 & 12.35 & 100 & 16,9 & 10,5 \\
\cline { 2 - 7 } & F3 & 6.16 & 12.25 & 100 & 13,3 & 13,25 \\
\cline { 2 - 7 } & F4 & 6.2 & 12.6 & 100 & 15.4 & 12.25 \\
\cline { 2 - 7 } & F5 & 6.2 & 12.2 & 100 & 14.2 & 11.75 \\
\hline
\end{tabular}

Data hasil pengujian bending pada table di atas, dilakukan perhitungan untuk mendapatkan tegangan bending dan momen bending seperti terlihat pada gambar berikut ini. 


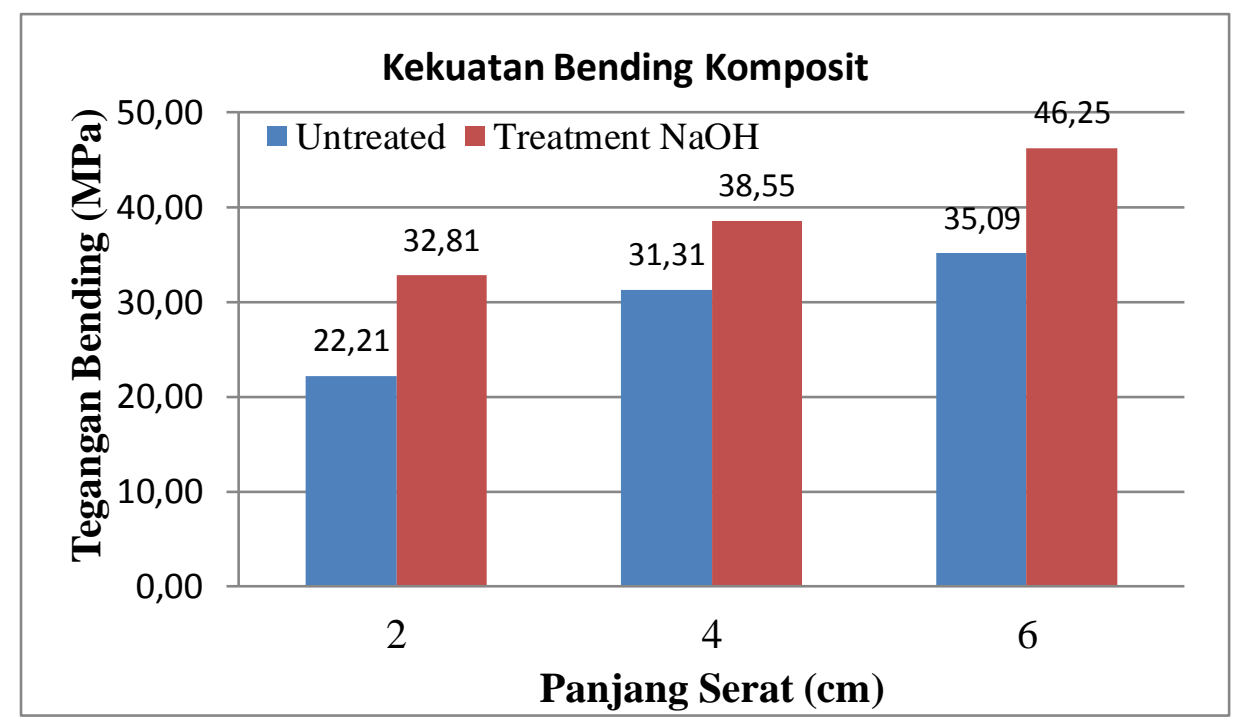

Gambar 2. Kekuatan Bending Komposit

Pada gambar di atas tampak bahwa komposit dengan panjang serat $6 \mathrm{~cm}$ memiliki kekuatan bending yang lebih tinggi dibandingkan dengan komposit yang diperkuat oleh serat $2 \mathrm{~cm}$ dan $4 \mathrm{~cm}$. Hasil ini menggambarka bahwa penguatan yang diberikan oleh serat agave cantula dengan panjang $6 \mathrm{~cm}$ lebih baik dibandingkan serat yang pendek sehingga kekuatan bendingnya juga lebih tinggi. Hal ini disebabkan karena Serat panjang mampu mendistribusikan beban dan tegangan secara perlahan dari pusat tegangan ke seluruh area komposit secara merata. Dari gambar, tampak pula bahwa komposit dengan serat yang diberi perlakuan alkali memiliki tegangan bending yang lebih tinggi dibandingkan dengan komposit yang diperkuat oleh serat tanpa perlakuan alkali. Hal ini disebabkan karena kekuatan ikatan interfacial antara serat dan matrik lebih baik dibandingkan dengan serat tanpa perlakuan. Serat yang diberi perlakuan alkali akan mengalami perubahan struktur pada permukaan serat, serat menjadi lebih bersih karena kotoran dan lignin yang menempel pada serat akan hilang akibat reaksi dari bahan kimia alkali. Sebaliknya pada serat yang tidak diberi perlakuan alkali, terdapat kotoran dan lignin yang masih menempel pada permukaan serat. Lignin ini membuat area antar muka dengan matrik menjadi lemah karena saat digunakan sebagai penguat pada matrik polimer. 


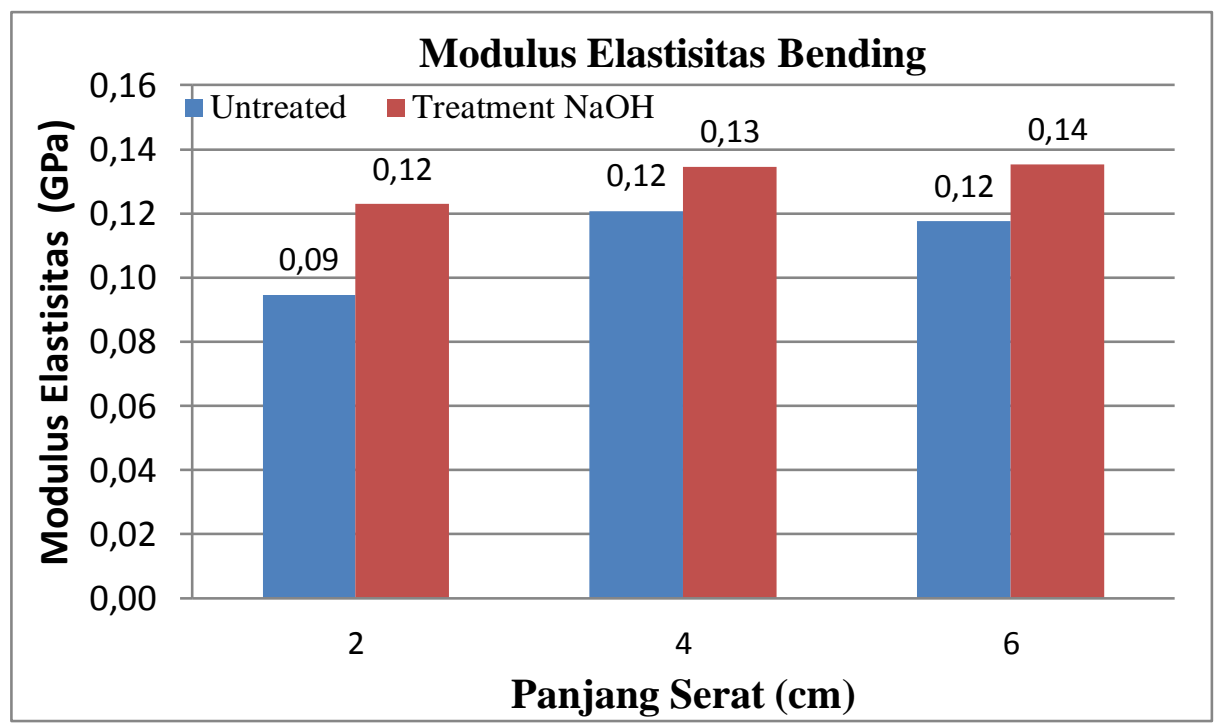

Gambar 3. Modulus Bending Komposit

Nilai modulus elastisitas bending komposit dapat dilihat pada gambar 2 di atas. Dari gambar menunjukkan bahwa komposit dengan penguatan serat yang lebih pendek memiliki nilai modulus elastisitas yang lebih rendah dibandingkan dengan serat yang lebih panjang. Selain itu, perlakuan $\mathrm{NaOH}$ juga memberikan pengaruh terhadap modulus elastisitas bending. Komposit yang diperkuat oleh serat yang diberi perlakuan $\mathrm{NaOH}$ memiliki nilai modulus elastisitas yang lebih tinggi dibandingkan dengan serat yang tanpa diberi perlakuan $\mathrm{NaOH}$. Hal ini juga terlihat pada nilai Momen Bending komposit seperti tampak pada gambar di bawah ini.

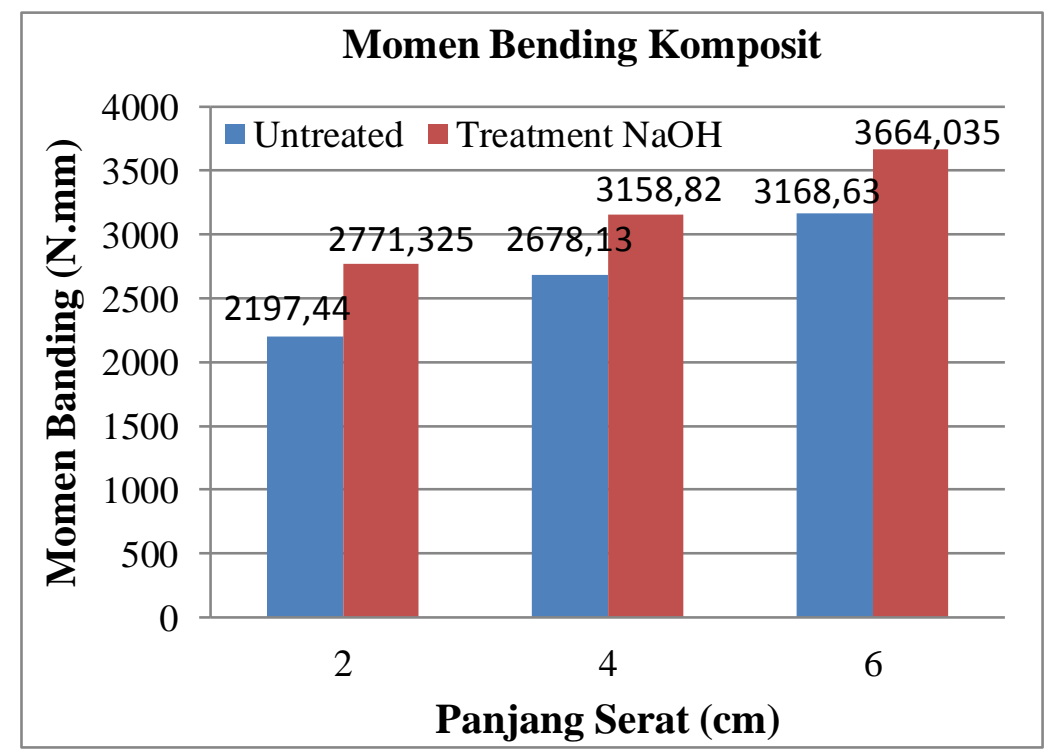

Gambar 4. Modulus Bending Komposit 
Gambar di atas menunjukkan gambaran jumlah gaya dari luar yang bekerja tegak lurus pada komposit. Tampak secara jelas bahwa gaya yang bekerja pada komposit dengan serat yang lebih pendek memiliki momen bending yang lebih rendah dibandingkan dengan serat yang panjang. Selain itu, komposit yang diperkuat oleh serat yang diberi perlakuan alkali juga memiliki nilai momen bending yang lebih besar dibandingkan dengan komposit yang berpenguat serat tanpa perlakuan. Dampak dari perlakuan alkali yang diberikan pada serat adalah perubahan struktur pada permukaan serat karena telah terlepasnya kotoran dan lignin yang menempel pada serat. Selain itu permukaan seratpun menjadi lebih kasar sehingga ikatan antar serat dan matrik menjadi lebih kuat. Sebaliknya ikatan antar muka antara serat dan matrik pada komposit berpenguat serat tanpa perlakukan menjadi lemah karena tidak compatibelnya serat dan matrik. Kotoran dan lignin pada serat menyebabkan area interfacial menjadi licin.

\section{KESIMPULAN}

Dari uraian ini, dapat diambil kesimpulan sebagai berikut:

a. Komposit yang diperkuat oleh serat panjang memiliki sifat bending yang lebih tinggi dibandingkan dengan serat pendek.

b. komposit yang diperkuat oleh serat yang diberi perlakuan alkali memiliki sifat bending yang lebih tinggi dibandingkan dengan serat tanpa perlakuan.

\section{DAFTAR PUSTAKA}

[1] Joshi, S.V., Drzal, L.T., Mohanty, A.K., dan Arora, S., “Are Natural Fiber Composites Environmentally Superior to Glass Fiber reinforced Composites", Composites: Part A, 35, 371-376, 2004.

[2] Debora Puglia, Marco Monti, Carlo Santulli, "Effect of Alkali and Silane Treatments on Mechanical and Thermal Behavior of Phormium tenax Fibers", Fibers and Polymers, 2013, Vol.14, No.3, 423-427

[3] S. I. Hossain, M. Hasan, Md. N. Hasan, and A. Hassan, "Effect of Chemical Treatment on Physical, Mechanical and Thermal Properties of Ladies Finger", Advances in Materials Science and Engineering, 2013. 
[4] Agnivesh Kumar Sinha, H.K.Narang, S. Bhattacharya, "Effect of Alkali Treatment on Surface Morphology of Abaca Fibre", Materials Today: Proceedings 4, 2017, 8993-8996

[5] Chaudhary, R., "Effect of Fiber Content on Thermal Behavior and Viscoelastic Properties of PALF/Epoxy and COIR/Epoxy Composites", Material Research Express, 2018.

[6] J. Nesimnasi, Kristomus Boimau, Yermias Pell, "Pengaruh perlakuan alkali pada serat agave cantula terhadap kekuatan tarik komposit polyester", Lontar Jurnal Teknik Mesin Undana, Vol 02, Nmr 1, hal 29 -37, 2015.

[7] Kristomus Boimau dan Theo Da Cunha, "Pengaruh Panjang Serat Terhadap Sifat Bending Komposit Poliester Berpenguat Serat Daun Gewang”, Proceeding Seminar Nasional Tahunan Teknik Mesin XIV (SNTTM XIV) Banjarmasin, 7-8 Oktober 2015

[8] Donni Pa, Yermias Pell, Wenseslaus Bunganaen, "Pengaruh perendaman $\mathrm{NaOH}$ Lima Persen terhadap Kekuatan tarik serat widuri”, Lontar Jurnal Teknik Mesin Undana, Vol 01, Nmr 02, hal 59-65, 2014.

[9] Prasad, GL Easwara, BS KeerthiGowda, and R. Velmurugan. "Prediction of Properties of Coir Fiber Reinforced Composite by ANN." Experimental Mechanics of Composite, Hybrid, and Multifunctional Materials, Volume 6. Springer International Publishing, (2014): 1-7.

[10] Agil Fitri Pamungkas, Dody Ariawan, Eko Surojo, and Joko Triyono. "Influence of Fiber Length on Flexural and Impact Properties of Zalacca Midrib fiber/HDPE by Compression Molding”, Proceeding The 3rd International Conference on Industrial, Mechanical, Electrical, and Chemical Engineering, 2018.

[11] N. Venkateshwaran, A. ElayaPerumal and M. S. Jagatheeshwaran, "Effect of fiber length and fiber content on mechanical properties of banana fiber/epoxy composite", Journal of Reinforced Plastics and Composites, 2011

[12] Effect of fiber length on mechanical properties of short carbon fiber reinforced PTFE composites Li Zhenhua, Rong Ruiya, Li Yunxuan and Li Jian, Advanced Materials Research Vols. $311-313$ (2011) pp 193-196, 